\title{
An integrated approach to preventing cardiovascular disease: community-based approaches, health system initiatives, and public health policy
}

\author{
This article was published in the following Dove Press journal: \\ Risk Management and Healthcare Policy \\ 3 September 2010 \\ Number of times this article has been viewed
}

\author{
Tina Karwalajtys' \\ Janusz Kaczorowski $\mathrm{i}^{2,3}$ \\ 'Department of Family Medicine, \\ McMaster University, Hamilton, ON, \\ Canada; ${ }^{2}$ Primary Care \& Community \\ Research, Child \& Family Research \\ Institute, Vancouver, BC, Canada; \\ ${ }^{3}$ Department of Family Practice, \\ University of British Columbia, \\ Vancouver, BC, Canada
}

\begin{abstract}
Cardiovascular disease (CVD) is largely the product of interactions among modifiable risk factors that are common in developed nations and increasingly of concern in developing countries. Hypertension is an important precursor to the development of CVD, and although detection and treatment rates have improved in recent years in some jurisdictions, effective strategies and policies supporting a shift in distribution of risk factors at the population level remain paramount. Challenges in managing cardiovascular health more effectively include factors at the patient, provider, and system level. Strategies to reduce hypertension and CVD should be population based, incorporate multilevel, multicomponent, and socioenvironmental approaches, and integrate community resources with public health and clinical care. There is an urgent need to improve monitoring and management of risk factors through community-wide, primary care-linked initiatives, increase the evidence base for communitybased prevention strategies, further develop and evaluate promising program components, and develop new approaches to support healthy lifestyle behaviors in diverse age, socioeconomic, and ethnocultural groups. Policy and system changes are critical to reduce risk in populations, including legislation and public education to reduce dietary sodium and trans-fatty acids, food pricing policies, and changes to health care delivery systems to explicitly support prevention and management of CVD.
\end{abstract}

Keywords: risk factors, blood pressure determination, community health services, community health planning, public health practice

\section{The burden of cardiovascular disease}

Cardiovascular diseases (CVDs) are largely the product of interactions among several modifiable risk factors that are too common in developed nations and increasingly of concern in developing countries. Effective, integrated health promotion programs and policies are our best tools to counteract the epidemics of obesity, diabetes, heart disease, and stroke that are emerging worldwide. ${ }^{1}$ Despite accumulation of evidence and established health care infrastructure, CVD remains a major public health challenge in North America and Western Europe. Furthermore, dramatic increases in cardiovascular risk factors and corresponding increases in prevalence and incidence of CVD have occurred in countries experiencing rapid development such as China, Thailand and Mexico. ${ }^{2}$ CVD accounted for $30 \%$ of an estimated 58 million deaths worldwide from all causes in $2005 .{ }^{3}$ Shifting the focus to an "upstream" approach of primary prevention integrated across different sectors and policies rather than a "downstream" approach
Correspondence: Janusz Kaczorowski UBC Department of Family Practice, Suite 320, 5950 University Boulevard, Vancouver, BCV6T IZ3 Canada

Tel $+\mathrm{I}-604-827-4396$

Fax $+|-604-827-4| 84$

Email janusz.kaczorowski@familymed. ubc.ca 
of medical care has the potential to decrease the individual, societal, and economic burden of CVD.

\section{Hypertension and CVD}

Hypertension is a key factor in the development of CVD and stroke, ${ }^{4}$ and people with other chronic conditions such as diabetes are at increased risk of hypertension complications. ${ }^{5,6}$ The global burden of blood pressure (BP)-related disease is substantial; over $54 \%$ of stroke, $47 \%$ of ischemic heart disease, and $13.5 \%$ of all deaths worldwide were attributed to high BP in 2001. ${ }^{7}$ The risk of developing hypertension increases with age such that the residual risk (lifetime cumulative incidence not adjusted for competing causes of mortality) of developing hypertension for middle-aged individuals is $90 \%{ }^{8}$ The recent Canadian Health Measures Survey estimated that 1 in 5 Canadian adults $(20 \%)$ had hypertension and another $20 \%$ had prehypertension (defined as systolic BP 120-139 mm Hg or diastolic BP 80-89 mm Hg). ${ }^{9}$ In the United States, approximately 73 million adults have hypertension. ${ }^{10}$ Previous population-based surveys found that $60 \%$ of the US adult population is affected, $27 \%$ with hypertension and $31 \%$ with prehypertension. ${ }^{11}$ The age- and sex-adjusted prevalence of hypertension was found to be higher in six European countries at 44\% among adults aged 19-64 years, using the threshold of $140 / 90 \mathrm{~mm} \mathrm{Hg} .^{12}$

Hypertension is costly to health care systems, contributing to the costs of treating CVD and stroke. Globally, the cost attributed to suboptimal BP (systolic BP $>115 \mathrm{~mm} \mathrm{Hg}$ ) was estimated at US\$372 billion in 2001, representing about $10 \%$ of overall health care expenditures. ${ }^{13}$ Conversely, complete control of high BP over a 10-year period was estimated to yield a savings of nearly $\$ 1$ trillion worldwide. ${ }^{13}$

The relationship between BP and CVD risk is strong, continuous, and independent of other risk factors. ${ }^{14}$ There is strong evidence that reduction in BP is associated with highly significant reductions in morbidity and mortality from CVD and stroke, as well as all-cause mortality. ${ }^{15,16}$ Evidence from randomized controlled trials supports promotion of healthy lifestyle choices to reduce BP, including adopting a weight-reducing diet, regular exercise, smoke-free environment, and restricted alcohol and sodium intake. ${ }^{17}$ There are also numerous cost-effective pharmacologic therapies to reduce $\mathrm{BP}^{18}$

Despite concerted efforts to establish and improve adherence to guidelines and best practices for the treatment of high BP in recent decades, ${ }^{19-22}$ many individuals with hypertension remain undiagnosed or undertreated and at risk of CVD morbidity and mortality. ${ }^{23,24}$ In Canada and the United States, prevalence of hypertension has remained largely unchanged over the last decade, although rates of treatment have improved. ${ }^{9,25}$ The Canadian Health Measures Survey (2007-2009) showed that an estimated 83\% of adults with hypertension were aware of their condition, $80 \%$ were taking medication, and $66 \%$ were controlled, ${ }^{9}$ compared with the $16 \%$ treated and controlled in a previous national survey (1985-1992), and 34\% remain uncontrolled. ${ }^{26}$ In the United States, BP control improved by $8.1 \%(29.2 \%-36.8 \%)$ in 2003-2004 compared with 1999-2000. ${ }^{25}$ More recent estimates indicate that $43 \%$ of Americans treated for hypertension do not reach the targets recommended by the Joint National Committee on Prevention, Detection, Evaluation, and Treatment of High Blood Pressure. ${ }^{27}$ Although the increase in treatment rates is promising, additional efforts are needed to reduce or delay incidence through lifestyle factors and control high BP among the substantial number of individuals who are not treated to recommended targets.

\section{Challenges in the prevention of hypertension and CVD}

Challenges in managing cardiovascular risk factors, including hypertension, more effectively include factors at the patient, health care provider, and system level. Once hypertension is diagnosed, BP is often not controlled to optimal levels. ${ }^{28,29}$ Among older adults, in particular, high BP is frequently underdiagnosed and undertreated. ${ }^{26}$ Older patients will frequently present with multiple health problems, which may reduce attention to detecting and treating elevated BP. Control of elevated BP may also be limited by uneven clinician adoption of newer thresholds, treatment protocols, and lifestyle recommendations ${ }^{30}$ or by clinician uncertainty regarding the patient's usual BP or the extent of medication nonadherence. ${ }^{27,31}$ Recommendations vary by country, with more aggressive treatment recommendations in Canada and the United States than in many Western European countries. ${ }^{32}$ Application of lower treatment thresholds and more intensive treatment regimens has been shown to support better control $^{32}$ and reduce the risk of CVD and stroke in populations, including patients aged 80 years or older. ${ }^{33}$ Nonetheless, health care providers may still hesitate to treat patients who are older or have comorbidities with sufficient intensity to reach recommended targets, ${ }^{34}$ even when hypertension is severe. $^{35}$

Patients' adherence to pharmacological antihypertensive treatment may be influenced by the cost, complexity, or 
side effects of multiple therapies. Patients and health care providers may also disagree about the need to intensify treatment. ${ }^{27}$ Lifestyle modification, including dietary changes, maintaining a healthy body weight, and increasing physical activity are evidence-based recommendations for hypertension prevention and control; however, behavioral changes are difficult for most people to achieve and maintain ${ }^{36}$ and are frequently underutilized in clinical practice. ${ }^{37}$

\section{Dietary factors}

The link between salt intake and increased BP has been well established through ecological, population, and prospective cohort studies and intervention trials, ${ }^{38}$ yet sodium consumption remains a particular concern in relation to increasing BP in Western populations. In the United States, $87 \%$ of adults are estimated to consume excess daily levels of salt $(>100 \mathrm{mmol}$ of sodium, $>2,400 \mathrm{mg}$ of sodium, or $>6,000 \mathrm{mg}$ of salt [sodium chloride]). ${ }^{39}$ It is difficult to accurately calculate sodium intake because a large proportion of our dietary salt is added in the processing and manufacturing of foods and in the fast-food industry; it is estimated that $75 \%$ of dietary sodium is added during food processing. ${ }^{40}$

Factors, which characterize the developed world and contribute to obesity, include a largely sedentary lifestyle, industrialization of food production and processing, pervasive retailing and marketing strategies, and environments not conducive to healthy lifestyle choices. ${ }^{41}$ Similar patterns of increasing obesity rates are seen in developing countries that have undergone rapid economic development leading to adoption of a Western lifestyle characterized by low physical activity and high consumption of inexpensive, energy-dense food. ${ }^{42}$ The rise in obesity is difficult to counteract without attention to the wider social, socioeconomic, and environmental factors that constitute barriers to implementation of healthy lifestyle changes.

\section{Strategies to reduce hypertension and CVD}

To address the complex and multilevel challenges limiting the optimal management of CVD risk worldwide, the strategies used will need to span the clinical and public health contexts and target patient-, provider-, and system-level factors.

Out-of-office BP measurements used to augment in-office data have potential to improve hypertension detection and management by reducing both the observer effects ${ }^{43}$ and the potential effects of the clinical setting. ${ }^{44-47}$ Ambulatory monitoring, previously the gold standard for BP assessment, is neither practical nor affordable for wide-scale application or monitoring over time and is inconvenient for patients.

Monitoring BP at home, with proper use of approved devices, is widely recommended ${ }^{48}$ and supported by evidence demonstrating the potential for improved control. A systematic review of the literature on home BP measurement concluded that it yields lower values than office measurement, with differences in systolic BP that increase with age and the level of BP measured in office. ${ }^{49}$ Home monitoring also correlates better with target organ damage and cardiovascular mortality than office measurement, enables prediction of sustained hypertension in patients with borderline hypertension, identifies normotensive patients with greater certainty, and can better assess drug efficacy. ${ }^{49}$

\section{Clinic and community approaches to increase treatment and control of hypertension}

A 2010 report on hypertension prevention and control in the United States pointed to a failure to translate public health and clinical knowledge into effective programs for prevention, treatment, and control of high BP as the reason for the persistence of hypertension as a "neglected disease" and emphasized the need for policy and system change to bridge public health and clinical care. ${ }^{50}$ Key recommendations include the following: a stronger focus on primary prevention through interventions to help reduce obesity, support healthy eating (decrease sodium intake and increase potassium intake) and increase physical activity; increased monitoring and reduction of sodium intake to meet current dietary guidelines; providing community-based support for individuals with hypertension through community health workers trained in dietary and physical activity counseling; and improved surveillance and reporting of hypertension to measure progress over time (including understudied populations: children, racial and ethnic minorities, the elderly, and selected socioeconomic groups). ${ }^{50}$

A review of effective strategies for BP control emphasized the value of strategies carried out at the community level. ${ }^{51}$ Community-based monitoring using an automated device is a promising approach to increase the number and accuracy of BP readings used in diagnosing and managing hypertension. ${ }^{45,52}$ Community programs can also provide opportunities for education and support for lifestyle modification.

\section{Dietary factors}

Since 1996, the United Kingdom's Consensus Action on Salt and Health group has been successful in waging a public 
health campaign to reduce salt added to foods, educate the public about the risks associated with excess salt, and translate evidence into public health policy. ${ }^{38} \mathrm{~A}$ detailed strategy with a target for salt reduction of $40 \%$ was implemented in 2003 based on measurement using 24-hour urinary sodium output, ${ }^{53}$ which showed that the average salt intake of $9.5 \mathrm{~g} / \mathrm{d}$ required a reduction of $3.5 \mathrm{~g}$, specifically in the amount of salt added in the food industry (7.6-4.6) and in cooking/ table use (1.4-0.9). Salt intake was reduced from 9.5 to $8.6 \mathrm{~g} / \mathrm{d}$ during the period of $2003-2008,{ }^{54}$ and the targets have been revised to ensure that salt intake will be reduced to $6 \mathrm{~g} / \mathrm{d}$ by $2012 .^{55}$

Gradual reduction in salt added to foods $(10 \%-20 \%$ at 1-2 year intervals) is a promising strategy, because such changes are not detectable by human salt taste receptors ${ }^{56}$ and do not pose preparatory or safety issues. A recent report by the Institute of Medicine stated that because the vast majority of Americans' sodium intake comes from salt added during preparation or processing of purchased food, a federal regulatory strategy will be implemented to incrementally reduce the maximum amount of salt that can be added to foods, beverages, and meals and effectively regulate salt as an additive with known risks. ${ }^{57} \mathrm{~A}$ regulatory strategy is a necessary step after 4 decades of public education campaigns and pressure on the food industry to voluntarily cut sodium have failed to substantially reduce sodium intake. ${ }^{57}$

Similarly, several European countries and selected jurisdictions in North America have implemented bans on trans fats, which have been shown to increase risk of CVD and stroke, ${ }^{58}$ specifically in prepared foods at food service outlets.

\section{Population approaches for chronic disease prevention}

There is no single solution to the challenge of CVD and its toll on populations and health care systems around the world. However, there is emerging consensus that for chronic disease prevention and management, population-based strategies are much more effective than those aimed at individuals. We see this in the World Health Organization's efforts to promote the use of multiple fiscal and educational policies as the first-line approach for CVD reduction in all settings. ${ }^{59}$

Health and longevity are influenced not only by individuals' characteristics but also by the characteristics of the communities in which people work and live and their wider societal circumstances. A population or public health approach to preventing disease acknowledges the importance of social and environmental factors in shaping health behaviors and access to health services. There is mounting empirical evidence to support the use of a broad approach for stroke and CVD prevention campaigns, through population-wide, community-level interventions that would enable residents to learn about and engage in healthier behaviors. ${ }^{60-64}$ Strategies include organizing communities to address health issues, educating residents via mass media and direct approaches, providing opportunities for screening risk factors, and changing local environments to promote healthier lifestyles. ${ }^{62,65}$

Awareness of the importance of interrelated social and environmental factors in shaping lifestyle behaviors has spurred efforts to make it easier for the public to make healthy choices, such as promoting "walkable" communities ${ }^{66}$ and increasing local availability of healthy foods. Behaviors such as smoking, poor diet, and lack of exercise are examples of modifiable risk factors for CVD that are frequently affected by broader interrelated factors, including socioeconomic status, ethnicity, neighborhood characteristics, and elements of the built environment. ${ }^{67-69}$ Recognition of the health system as an important socioenvironmental determinant has prompted interest in how organizations that develop and deliver chronic disease prevention and healthy lifestyle programs within health systems can contribute to reducing the chronic disease burden. ${ }^{70}$

Foremost among strategies is the need to adopt a population-based approach, to move away from an individual medical focus, to facilitate broader education, and to monitor linkage to treatment at the community or population level. Strategies that encompass a population perspective while also addressing individual determinants of risk are promising. ${ }^{71}$ An example is community-based interventions that aim to decrease the burden of CVD by shifting the distribution of risk factors at the population level, which may include reducing the proportion of a population with high $\mathrm{BP} .^{72}$ Health interventions based on community organization and development models emphasize partnerships, collaboration, and community mobilization to maximize coverage and capitalize on diffusion effects. ${ }^{73}$

Early population health efforts in developed countries, from the 1970 s to 1990 s, focused primarily on screening. The conditions for implementing screening programs included weighing the potential benefits and harms of screening, establishing an expectation that early detection would yield better outcomes, and ensuring that follow-up is appropriate and feasible. ${ }^{74-76}$ More recent work in community-level health 
promotion has incorporated multilevel, multicomponent, socioenvironmental approaches that include medical, behavioral, and community development strategies. ${ }^{77}$ Such programs use many points of leverage (eg, individuals, organizations, social networks, communities, and policymakers) and seek an optimal blend of strategies to effect change in a community. ${ }^{78}$

\section{Cardiovascular health programs in communities}

Several large-scale community-based CVD prevention campaigns showed promising results, ${ }^{79,80}$ however, subsequent efforts have produced only modest, inconsistent effects on risk factors without any significant effects on health outcomes. ${ }^{81-83}$ Much has been written about the varying success of major cardiovascular prevention initiatives, such as the Franklin, Minnesota, North Karelia, and Stanford projects. ${ }^{80,84-86}$ Some smaller-scale community interventions based in primary care, ${ }^{87,88}$ including nurse-mediated interventions, ${ }^{89}$ have shown reductions in risk factors.

Although community-based CVD prevention interventions have the potential to shift the burden of risk in populations, the effectiveness of directly assessing BP for elevated levels has yet to be established. In fact, although communitybased BP screening programs have a long history, relatively few of them have been rigorously evaluated.

\section{Integration of community resources}

Multidisciplinary teams are increasingly favored as a means of delivering comprehensive primary care. Teams might include, eg, family physicians, nurse practitioners, social workers, dieticians, pharmacists, and other allied health professionals. A systematic review of controlled trials examining quality improvement interventions for hypertension management found that interdisciplinary team-based care was the only strategy that significantly improved BP. ${ }^{90}$ Further examination of the potency of team-based care interventions involving pharmacists or nurses concluded that team-based care was associated with improved BP control and that specific components, such as pharmacist-recommended medication to physicians or counseling about lifestyle modification, appeared to determine the potency of the intervention. ${ }^{20}$

\section{Pay-for-performance initiatives}

Additional system-level interventions include "pay-forperformance" schemes to encourage physicians to meet targets for optimal care delivery. Although programs are established or in development in the United Kingdom, United States, ${ }^{91-93}$ Canada, ${ }^{94}$ Australia, ${ }^{95}$ Germany, ${ }^{96}$ the Netherlands, ${ }^{97}$ New Zealand, ${ }^{98}$ and elsewhere, research to date examining the effectiveness of financial incentives for health care providers in maximizing delivery of preventive care services or chronic disease management is limited, inconclusive, and difficult to generalize to other settings.

Provider-incentive approaches may also have value in improving management of chronic disease. A study in England to determine the effect of a pay-for-performance scheme on the quality of care of patients with asthma, diabetes, or coronary heart disease in family practice found that the rate of improvement in the quality of care increased for asthma and diabetes $(P<0.001)$ but not for heart disease. ${ }^{99}$ The scheme accelerated an underlying trend of improvements in quality of care for two conditions; however, the gains reached a plateau after 1 year, once targets were reached, with improvement in diabetes care continuing at the preintervention rate. ${ }^{99}$ An ambitious pay-for-performance program specifically for management of hypertension in the United Kingdom has shown that generous financial incentives are associated with meeting performance targets for aspects of care among patients with hypertension; however, much of this achievement may be attributable to coexisting quality improvement initiatives. ${ }^{100}$ As pay-for-performance approaches gain momentum, it is important to note the emergence of unanticipated outcomes, such as reductions in continuity of care ${ }^{99}$ or other aspects of quality that may result from valuing what can be measured in patient care over what cannot, and the need for multilayered and sustainable programs to achieve improvements over the long term. ${ }^{101}$

\section{Electronic medical or health records}

A range of electronic systems and tools have been investigated for effectiveness in improving management of chronic diseases, including decision support systems such as drug-dosing systems and computer-generated reminder systems for preventive care services. Still, research on the most effective implementation strategy for guideline-based decision support systems is lacking. Two recent systematic reviews of electronic guideline-based clinical decision support systems in ambulatory care settings concluded that there is little or mixed evidence for the effectiveness of electronic multidimensional guidelines. ${ }^{102,103}$

Nonetheless, the increasing implementation of electronic medical records (EMRs) or electronic health records is expected to facilitate new approaches to enhance detection 
and management of chronic disease, including hypertension. Although the effect of EMR use in primary care on quality measures has been negligible in general, there is some evidence to suggest that the availability and use of specific EMR components or features may improve delivery of certain preventive care services. ${ }^{104}$ This finding supports a more tailored approach to the development and implementation of EMRs. It seems likely that electronic data capture, including capabilities for disease registries, can provide opportunities for quality improvement and policy making to meet local needs.

\section{Multilevel partnerships}

In the United States, the Institute of Medicine is calling for resources to implement a broad suite of promising populationbased policy and system approaches at the federal, state, and local levels to combat hypertension. ${ }^{50}$ In particular, the Division of Heart Disease and Stroke Prevention is tasked with developing programs using community health workers for deployment in high-risk communities, with appropriate linkage to primary care services. ${ }^{50}$

\section{Multidisease focus}

Given that a common set of risk factors is implicated in multiple chronic diseases, similar strategies are expected to be important for their prevention, detection, and management of a multitude of diseases and conditions. Public health programs are also aiming to address risk factors common to multiple major noncommunicable diseases. ${ }^{105}$ Health systems research has led to the development of theoretical models that help explain how various components of multifaceted programs work to improve the health of community members. For example, Wagner's chronic care model ${ }^{106}$ posits that improvement in care requires an approach that incorporates patient-, provider-, and system-level interventions. This model has been expanded to include addressing risk behaviors in primary care, with an emphasis on linking community-based programs and patient self-management support. The outcome has been the improved care at both the population and individual levels. ${ }^{107}$

The broader value of community-based health initiatives is that learning and infrastructure can be applied to address other chronic diseases, specifically community or population approaches, such as community mobilization and partnership with care providers, accurate direct assessment of risk factors, and delivery of peer education. Additionally, a common toolbox of methodological approaches for evaluation can be applied to the development and evaluation of diverse interventions. This is particularly important in establishing the reach, effectiveness, scalability, and generalizability of programs and the contributions of specific components.

\section{Socioenvironmental approaches}

The need to focus on primary and secondary prevention is important, given the preponderance of evidence for risk reduction through lifestyle modification and pharmacologic treatment. There is a need to go beyond individual lifestyle modification to address more fundamental determinants of health. Interventions to promote to healthier lifestyles have generally been limited in scope and not very successful in the longer term, mainly because of the difficulty in addressing the broader societal factors influencing behaviors. ${ }^{108-110}$ A multilevel approach to prevention is essential; eg, the framework proposed by Sacks et al ${ }^{111}$ to address "upstream" policies to make healthy eating and physical activity easier, "midstream" policies to influence population behaviors, and "downstream" policies to support health services and clinical care. It is particularly difficult to intervene in food production, processing, and marketing, yet this is where the bulk of excess sodium, fat, and calories enter the food supply. Achieving a population-level reduction in the risk of metabolic disease may also require a paradigm shift from commercial aspects of food production to the wider social, cultural, economic, and political significance of dietary habits. ${ }^{112}$

Economic strategies are another avenue for influencing food choices. To date, studies on food pricing policies, such as modest additional taxes on less healthy, energy-dense foods or subsidies on healthier choices, have not shown significant changes in body mass index or obesity rates. ${ }^{110}$ More substantive pricing differences are likely to have a greater effect; however, implementing such policies is difficult, given the opposition of the fast-food industry and many consumers who value their freedom of choice.

Within closed systems such as schools and workplaces, taxing or subsidizing food choices has shown greater promise in influencing food behavior. ${ }^{113}$ Localized initiatives to remove sugar-sweetened soft drinks and other junk food from schools and hospitals, or in the vicinity of schools, have been implemented; however, little research data are available evaluating the effectiveness of these strategies. Further research is needed to determine the effectiveness of fiscal pricing interventions in combating obesity rates. ${ }^{114}$

The physical and built environment certainly plays a role and has been well examined in relation to health. Substantial gains in community health will require structural changes in 
urban planning (ie, "walkable" communities), transportation, public safety, education, and health promotion.

\section{Conclusion}

After decades of investment of health care and research dollars to better understand and combat vascular disease, the persistent challenges of hypertension, CVD, and stroke worldwide point to the complexity of the problem and underline the need for resourceful and coalescent prevention strategies. Despite the large number of community-based CVD or BP screening programs that have been described in the literature over the last 30 years, relatively few of them have been well evaluated or scaled up in a sustainable manner at the population level.

Although a number of approaches appear promising, evidence from well-designed trials is generally lacking, and most interventions are not evaluated at the population level. Implementing population approaches requires substantial commitment and resources. On-the-ground programs should be evaluated using rigorous methodology to increase the evidence base for community-based or population-based CVD and stroke prevention. This can be achieved through programs of research that focus on both development and evaluation of interventions within each implementation. Where possible, it is important to look at testing individual components of interventions and effects at the population level. This will allow further development of promising components, such as lay health educators, community mobilization, and other outreach strategies, linkage to primary care, and accessing groups that are underserviced or underresearched.

Further, by recognizing essential aspects vs flexible aspects of health promotion interventions, we can expand the "toolbox" of effective approaches and adapt programs for implementation in diverse communities or municipalities. Continued research should prioritize the generation and use of community-specific health data through primary care-linked initiatives. Integrated collection of data on hypertension and other CVD and stroke risk factors in communities can aid in surveillance of chronic disease in populations and public health planning.

Because shifting risk levels in populations is a complex challenge, developing new approaches to support dietary and physical activity modification in diverse age, socioeconomic, and ethnocultural groups is critical. Effective strategies are likely to vary, according to the needs and preferences of populations. Addressing the complex determinants of lifestyle behaviors will also require increased cross-linkages of health care with other government sectors to effect changes in urban planning and public services to aid health. Balancing the funding and infrastructure for primary and secondary prevention of CVD and stroke is important, given the widespread and well-established risk factors and the potential health system savings in treating "downstream" illness.

\section{Disclosure}

The authors report no conflicts of interest in this work.

\section{References}

1. Evans R, Barer M, Marmor T, editors. Why Are Some People Healthy and Others Not? The Determinants of Health of Populations. New York, NY: Aldine De Gruyter; 1994.

2. Popkin BM. The nutrition transition: an overview of world patterns of change. Nutr Rev. 2004;62:S140-S143.

3. World Health Organization. Preventing chronic disease: a vital investment. Geneva, Switzerland: WHO; 2005.

4. Pearson TA, Blair SN, Daniels SR, et al. AHA guidelines for primary prevention of cardiovascular disease and stroke: 2002 update: consensus panel guide to comprehensive risk reduction for adult patients without coronary or other atherosclerotic Vascular Diseases. Circulation. 2002;106:388-391.

5. Mancia G. Optimal control of blood pressure in patients with diabetes reduces the incidence of macro and microvascular events. J Hypertens Suppl. 2007;25(1):S7-S12.

6. The Hypertension in Diabetes Study Group. Hypertension in Diabetes Study (HDS); Part II: increased risk of cardiovascular complications in hypertensive type 2 diabetic patients. J Hypertens. 1993;11:319-325.

7. Lawes CM, vander Hoorn S, Rodgers A; International Society of Hypertension. Global burden of blood-pressure-related disease, 2001. Lancet. 2008;371:1513-1518.

8. Vasan RS, Beiser A, Seshadri S, et al. Residual lifetime risk for developing hypertension in middle-aged women and men: the Framingham Heart Study. JAMA. 2002;287(8):1003-1010.

9. Wilkins K, Campbell NRC, Joffres MR, et al. Blood pressure in Canadian adults. Health Rep. 2010;21(1):37-46.

10. American Heart Association. Heart disease and stroke statistics: 2009 update. Dallas, TX: American Heart Association; 2009.

11. Wang Y, Wang QJ. The prevalence of prehypertension and hypertension among US adults according to the new joint national committee guidelines: new challenges of the old problem. Arch Intern Med. 2004; 164:2126-2134.

12. Wolf-Maier K, Cooper RS, Banegas JR, Giampaoli S, Hense HW, Joffres M. Hypertension prevalence and blood pressure levels in 6 European countries, Canada and the United States. JAMA. 2003;289:2363-2369.

13. Gaziano TA, Bitton A, Anand S, Weinstein MC; International Society of Hypertension. The global cost of nonoptimal blood pressure. J Hypertens. 2009;27:1472-1477.

14. Elliott P, Stamler J. Primary prevention of high blood pressure. In: Marmot M, Elliot P, editors. Coronary Heart Disease Epidemiology. New York, NY: Oxford University Press; 2005:751-768.

15. MacMahon S, Peto R, Cutler J, et al. Blood pressure, stroke, and coronary heart disease; Part I: prolonged differences in blood pressure prospective observational studies corrected for the regression dilution bias. Lancet. 1990;335:765-774.

16. Collins R, Peto R, MacMahon S, et al. Blood pressure, stroke, and coronary heart disease; Part II: short-term reductions in blood pressure overview of randomized drug trials in their epidemiological context. Lancet. 1990;335:827-838.

17. Dickinson HO, Mason JM, Nicolson DJ, et al. Lifestyle interventions to reduce raised blood pressure: a systematic review of randomized controlled trials. J Hypertens. 2006;24(2):215-233. 
18. Khan NA, McAlister FA, Rabkin SW, et al. The 2006 Canadian Hypertension Education Program recommendations for the management of hypertension; Part II: therapy. Can J Cardiol. 2006;22(7): 583-593.

19. Tobe SW, Touyz RM, Campbell NR; Canadian Hypertension Education Program. The Canadian Hypertension Education Program: a unique Canadian knowledge translation program. Can J Cardiol. 2007; 23(7):551-555.

20. Carter BL, Rogers M, Daly J, Zheng S, James PA. The potency of team-based care interventions for hypertension: a meta-analysis. Arch Intern Med. 2009;169(19):1748-1755.

21. Thompson A, Campbell NR, Cloutier L, et al. Tackling the burden of hypertension in Canada: encouraging collaborative care. Can Fam Physician. 2008;54(12):1659-1662, 1664-1667.

22. Germino FW. The management and treatment of hypertension. Clin Cornerstone. 2010;9 Suppl 3:S27-S33.

23. Campbell NR, So L, Amankwah E, Quan H, Maxwell C; Canadian Hypertension Education Program Outcomes Research Task Force. Characteristics of hypertensive Canadians not receiving drug therapy. Can J Cardiol. 2008;24(6):485-490.

24. Trilling JS, Froom J. The urgent need to improve hypertension care. Arch Fam Med. 2000;9(9):794-801.

25. Ong KL, Cheung BM, Man YB, Lau CP, Lam KS. Prevalence, awareness, treatment, and control of hypertension among United States adults 1999-2004. Hypertension. 2007;49(1):69-75.

26. Joffres M, Ghadirian P, Fodor JG, Petrasovits A, Chockalingam A, Hamet P. Awareness, treatment, and control of hypertension in Canada. Am J Hypertens. 1997;10(10):1097-1102.

27. Pavlik VN, Greisinger AJ, Pool J, Haidet P, Hyman DJ. Does reducing physician uncertainty improve hypertension control?: rationale and methods. Circ Cardiovasc Qual Outcomes. 2009;2(3):257-263.

28. Parati G. Blood pressure variability, target organ damage and antihypertensive treatment. J Hypertens. 2003;21(10):1827-1830.

29. Petrella RJ, Merikle EP, Jones J. Prevalence, treatment and control of hypertension in primary care: gaps, trends and opportunities. J Clin Hypertens (Greenwich). 2007;9(1):28-35

30. Mosca L, Linfante AH, Benjamin EJ, et al. National study of physician awareness and adherence to cardiovascular disease prevention guidelines. Circulation. 2005;111(4):499-510.

31. Heisler M, Hogan MM, Hofer TP, Schmittdiel JA, Pladevall M, Kerr EA. When more is not better: treatment intensification among hypertensive patients with poor medication adherence. Circulation. 2008;117(22):2884-2894.

32. Wang YR, Alexander GC, Stafford RS. Outpatient hypertension treatment, treatment intensification, and control in Western Europe and the United States. Arch Intern Med. 2007;167(2):141-147.

33. O'rourke MF, Namasivayam M, Adji A. Treatment of hypertension in patients 80 years of age or older. Minerva Med. 2009;100(1):25-38.

34. Kesarwani M, Perez A, Lopez VA, Wong ND, Franklin SS. Cardiovascular comorbidities and blood pressure control in stroke survivors. J Hypertens. 2009;27(5):1056-1063.

35. Borzecki AM, Kader B, Berlowitz DR. The epidemiology and management of severe hypertension. J Hum Hypertens. 2010;24(1):9-18.

36. Orleans CT. Promoting the maintenance of health behavior change: recommendations for the next generation of research and practice. Health Psychol. 2000;19 Suppl 1:76-83.

37. Heaton PC, Frede SM. Patients' need for more counseling on diet, exercise, and smoking cessation: results from the National Ambulatory Medical Care Survey. J Am Pharm Assoc (2003). 2006;46(3): 364-369.

38. Feng JH, Graham AM. Reducing population salt intake worldwide: from evidence to implementation. Prog Cardiovasc Dis. 2010;52: $363-382$.

39. National Center for Health Statistics. Healthy People 2010 Progress Review. Focus Area 19: Nutrition and Overweight Presentation. Available from: http://www.cdc.gov/nchs/ppt/hp2010/focus_areas/fa19_2. ppt\#803,14,Slide 14. Published 2008. Accessed Apr 18, 2010.
40. Barr SI. Reducing dietary sodium intake: the Canadian context. Appl Physiol Nutr Metab. 2010;35:1-8.

41. Hossain P, Kawar B, El Nahas M. Obesity and diabetes in the developing world: a growing challenge. 3. N Engl J Med. 2007;356:213-215.

42. Caballero B. A nutrition paradox: underweight and obesity in developing countries. $N$ Eng J Med. 2005;352:1514-1516.

43. Neitert PJ, Wessell AM, Feifer C, Ornstein SM. Effect of terminal digit preference on blood pressure measurement and treatment in primary care. Am J Hypertens. 2006;19(2):147-152.

44. Parati G, Valentini M. Do we need out-of-office blood pressure in every patient? Curr Opin Cardiol. 2007;22(4):321-328.

45. Chambers LW, Kaczorowski J, Levitt C, Karwalajtys T, McDonough B, Lewis J. Blood pressure self-monitoring in pharmacies. Building on existing resources. Can Fam Physician. 2002;48:1594-1595, 1602-1604.

46. Sullivan SM, Kaczorowski J, Myers MG, Karwalajtys T, Chambers LW. Use of automated blood pressure measurement to reduce white coat response in a pharmacy setting. Can J Cardiol. 2007;23(Suppl C):85C. http://www.pulsus.com/ccc2007/abs/0206.htm.

47. Pickering TG. The natural history of hypertension: prehypertension or masked hypertension? J Clin Hypertens. 2007;9.

48. Canadian Hypertension Education Program. 2110 Key Messages. Available from: http://hypertension.ca/chep/summaries/key-messages/. Accessed April 18, 2010.

49. Verberk WJ, Kroon AA, Kessels AG, de Leeuw PW. Home blood pressure measurement: a systematic review. J Am Coll Cardiol. 2005; 46(5):743-751.

50. Committee on Public Health Priorities to Reduce and Control Hypertension in the US Population; Institiute of Medicine. A population-based policy and systems change approach to prevent and control hypertension (executive summary). Washington, DC: National Academies of Sciences Press. Available from: http://www.nap.edu/catalog/12819. html. Accessed Apr 18, 2010.

51. Welch VLL, Hill MN. Effective strategies for blood pressure control. Cardiol Clin. 2002;20:321-333,vii.

52. Myers MG. Automated blood pressure measurement in routine clinical practice. Blood Press Monit. 2006;11:59-82.

53. Henderson L, Irving K, Gregory J, et al, editors. National Diet and Nutrition Survey: adults aged 19 to 64. Vitamin and mineral intake and urinary analytes. Vol 3. London, England: TSO; 2003: 127-136.

54. Food Standards Agency. Dietary sodium levels surveys. Available from: http://www.food.gov.uk/science/dietarysurveys/urinary. Published 2008. Accessed Apr 18, 2010.

55. Food Standards Agency. Agency publishes 2012 salt reduction targets. Available from: http:/www.food.gov.uk/news/newsarchive/2009/may/ salttargets. Published 2008. Accessed April 18, 2010.

56. Girgis S, Neal B, Prescott J, et al. A one-quarter reduction in the salt content of bread can be made without detection. Eur J Clin Nutr. 2003; 57:616-620.

57. Institute of Medicine Food and Nutrition Board, Committee on Strategies to Reduce Sodium Intake. Strategies to Reduce Sodium Intake in the United States (Consensus Report). Available from: http://www.iom. edu/Reports/2010/Strategies-to-Reduce-Sodium-Intake-in-the-UnitedStates.aspx. Accessed April 18, 2010.

58. Mozaffarian D, Katan MB, Ascherio A, Stampfer MJ, Willett WC. Trans fatty acids and cardiovascular disease. $N$ Eng $J$ Med. 2006; 354(15):1601-1613.

59. World Health Organization. Available from: http://www.who.int/ dietphysicalactivity/publications/facts/cvd/en/. Published 2008. Accessed Jan 20, 2008

60. Sargent RP, Shepard RM, Glantz SA. Reduced incidence of admissions for myocardial infarction associated with public smoking ban: before and after study. BMJ. 2004;328:977-980.

61. Bartecchi C. A city-wide smoking ordinance reduces the incidence of acute myocardial infarction. Paper presented at: American Heart Association Annual Scientific Sessions; 2005 Nov 14; Dallas, Texas. 
62. Schooler C, Farquhar JW, Fortmann SP, Flora JA. Synthesis of findings and issues from community prevention trials. Ann Epidemiol. 1997; 7:S54-S68.

63. Pearson TA, Wall S, Lewis C, et al. Dissecting the "black box" of community intervention: lessons from community-wide cardiovascular disease prevention programs in the US and Sweden. Scand J Public Health. 2001;29:69-78.

64. Dobbins M, Beyers J. The effectiveness of community-based heart health projects: a systematic overview update. Paper presented at: Ontario Public Health Research, Education and Development Program; 1999; Ontario, Canada.

65. Stone EJ, Pearson TA, Fortmann SP, McKinlay JB. Community-based prevention trials: challenges and directions for public health practice, policy, and research. Ann Epidemiol. 1997;7:S113-S120.

66. Saelens BE, Sallis JF, Black JB, Chen D. Neighbourhood-based differences in physical activity: an environment scale evaluation. Am J Public Health. 2003;93:1552-1558.

67. Kirkpatrick S, Tarasuk V. The relationship between low income and household food expenditure patterns in Canada. Public Health Nutr. 2003;6(6):589-597.

68. Berrigan D, Troiano RP. The association between urban form and physical activity in US adults. Am J Prev Med. 2002;23 Suppl 2: 74-79.

69. Frank LD, Schmid TL, Sallis JF, Chapman J, Saelens BE. Linking objectively measured physical activity with objectively measured urban form: findings from SMARTRAQ. Am J Prev Med. 2005;28 (2 Suppl 2):117-125.

70. Hanusaik N, O’Loughlin JL, Kishchuk N, Eyles J, Robinson K, Cameron R. Building the backbone for organisational research in public health systems: development of measures of organisational capacity for chronic disease prevention. J Epidemiol Community Health. 2007;61:742-749.

71. Merzel C, D'Affliti J. Reconsidering community-based health promotion: promise, performance, and potential. Am J Public Health. 2003; 93(4):557-574.

72. Rose G. The Strategy of Preventive Medicine. Oxford: Oxford University Press Inc; 1992.

73. Minkler M, Wallerstein NB. Improving health through community organization and community building. In: Glanz K, Rimer BK, Lewis FM, editors. In Health Behavior and Health Education: Theory, research, and practice. San Francisco: Jossey-Bass; 2002:279-311.

74. Engelgau MM, Venkat Narayan KM, Herman WH. Screening for type 2 diabetes. Diabetes Care. 2000;23:1563-1580.

75. Shah CP. Public Health and Preventive Medicine in Canada. 4th ed. Toronto: University of Toronto Press; 1998:40-42, 168-170.

76. Wilson JMG, Junger G. The Principles and Practice of Screening for Disease. Public Health Papers No. 34. Geneva: WHO; 1968.

77. Baum F. Measuring effectiveness in community-based health promotion. In: Davies JK, Macdonald G, editors. Quality, Evidence and Effectiveness in Health Promotion. Striving for Certainties. London: Routledge; 1998:68-89.

78. Edwards N. Investing in multi-level and multi-strategy disease and illness prevention (Banff conference). Available from: http:// www.uleth.ca/man/research/centres/chmr/conferences/2005/files/ Investing\%20 in\%20MIPs\%20Banff.pdf. Published 2005. Accessed Jul 24, 2007.

79. Farquhar JW, Maccoby N, Wood PD, et al. Community education for cardiovascular health. Lancet. 1977;1:1192-1195.

80. Puska P, Salonen JT, Nissinen A, et al. Change in risk factors for coronary heart disease during 10 years of a community intervention programme (North Karelia project). Br Med J (Clin Res Ed). 1983; 287(6408):1840-1844.

81. Winkleby MA, Feldman HA, Murray DM. Joint analysis of three US community intervention trials for reduction of cardiovascular disease risk. J Clin Epidemiol. 1997;50:645-658.

82. Shea S, Basch CE. A review of five major community-based cardiovascular disease prevention programs. Part I: rationale, design and theoretical framework. Am J Health Promot. 1990;4:203-213.
83. Shea S, Basch CE. A review of five major community-based cardiovascular disease prevention programs; Part II: intervention strategies, evaluation methods, and results. Am J Health Promot. 2006;4(4): 279-287.

84. Burgess-Record N, Harris DE, Record SS, Gilbert-Arcari J, DeSisto M, Bunnell S. Mortality impact of an integrated community cardiovascular health program. Am J Prev Med. 2000;19(1):30-38.

85. Luepker RV, Rastam L, Hannan PJ, et al. Community education for cardiovascular disease prevention. Morbidity and mortality results from the Minnesota Heart Health Program. Am J Epidemiol. 1996; 144(4): 351-362.

86. Farquhar JW, Fortmann SP, Flora JA, et al. Effects of communitywide education on cardiovascular disease risk factors. The Stanford FiveCity Project. JAMA. 1990;264(3):359-365.

87. Rossouw JE, Jooste PL, Chalton DO, et al. Community-based interventions: the Coronary Risk Factor Study (CORIS). Int J Epidemiol. 1993;22:428-438.

88. Wrench JGA. Coronary heart disease: account of a preventive clinic in general practice. J R Coll Gen Prac. 1984;34:477-481.

89. Wonderling D, Langham S, Buxton M, et al. What can be concluded from the Oxcheck and British family heart studies: commentary on cost effectiveness analyses. BMJ. 1996;312:1274-1278.

90. Walsh JM, McDonald KM, Shojania KG, et al. Quality improvement strategies for hypertension management: a systematic review. Med Care. 2006;44(7):646-657.

91. Rosenthal MB, Frank RG, Li Z, Epstein AM. Early experience with pay-for-performance: from concept to practice. JAMA. 2005;294(14): 1788-1793.

92. Epstein AM. Pay for performance at the tipping point. $N$ Engl J Med. 2007;356:515-517.

93. Epstein AM. Paying for performance in the United States and abroad. N Engl J Med. 2006;355:406-408.

94. Pink GH, Brown AD, Studer ML, Reiter KL, Leatt P. Pay-for-performance in publicly financed healthcare: some international experience and considerations for Canada. Healthc Pap. 2006;6:8-26.

95. Medicare Australia. Practice Incentives Program (PIP). Available from: http://www.medicareaustralia.gov.au/provider/incentives/pip/ index.shtml. Published 2010. Accessed May 18, 2010.

96. Greb S, Focke A, Hessel F, Wasem J. Financial incentives for disease management programmes and integrated care in German social health insurance. Health Policy. 2006;78:295-305.

97. Custers T, Arah OA, Klazinga NS. Is there a business case for quality in The Netherlands? A critical analysis of the recent reforms of the health care system. Health Policy. 2007;82:226-239.

98. Perkins R, Seddon M. Quality improvement in New Zealand healthcare; Part V: measurement for monitoring and controlling performance - the quest for external accountability. $N Z$ Med J. 2006;119: U2149.

99. Campbell SM, Reeves D, Kontopantelis E, Sibbald B, Roland M. Effects of pay for performance on the quality of primary care in England. N Engl J Med. 2009;361(4):368-378.

100. Doran T, Fullwood C. Pay for performance: is it the best way to improve control of hypertension? Curr Hypertens Rep. 2007;9(5):360-367.

101. Doran T, Roland M. Lessons from major initiatives to improve primary care in the United Kingdom. Health Aff (Millwood). 2010;29: 1023-1029.

102. Heselmans A, van de Velde S, Donceel P, Aertgeerts B, Ramaekers D. Effectiveness of electronic guideline-based implementation systems in ambulatory care settings: a systematic review. Implement Sci. 2009; $4: 82$.

103. Bryan C, Boren SA. The use and effectiveness of electronic clinical decision support tools in the ambulatory/primary care setting: a systematic review of the literature. Inform Prim Care. 2008;16(2):79-91.

104. Poon EG, Wright A, Simon SR, Jenter CA, Kaushal R, Volk LA. Relationship between use of electronic health record features and health care quality: results of a statewide survey. Med Care. 2010;48(3): 203-209. 
105. Wolbeck Minke S, Smith C, Plotnikoff RC, Khalema E, Raine K. The evolution of integrated chronic disease prevention in Alberta, Canada. Prev Chronic Dis. 2006;3(3):A102. Epub 2006 Jun 15.

106. Wagner EH. Chronic disease management: what will it take to improve care for chronic illness? Eff Clin Pract. 1998;1(1):2-4.

107. Hung DY, Rundall TG, Tallia AF, Cohen DJ, Halpin HA, Crabtree BF. Rethinking prevention in primary care: applying the chronic care model to address health risk behaviors. Milbank Q. 2007;85(1):69-91.

108. Rosenheck R. Fast food consumption and increased caloric intake: a systematic review of a trajectory towards weight gain and obesity risk. Obes Rev. 2008;9(6):535-547.

109. Finkelstein EA, Zuckerman L. The Fattening of America. How The Economy Makes Us Fat, If It Matters and What To Do About It. Hoboken, New Jersey: John Wiley \& Sons, 2008. Published simultaneously in Canada.

110. Powell LM, Chaloupka FJ. Food prices and obesity: evidence and policy implications for taxes and subsidies. Milbank Q. 2009;87(1): 229-257.
111. Sacks G, Swinburn B, Lawrence M. Obesity policy action framework and analysis grids for a comprehensive policy approach to reducing obesity. Obes Rev. 2009;10(1):78-86.

112. Kaczorowski J, Shubair M, Kaczorowski M. Fast food and the global epidemic of type 2 diabetes: are we doomed to become obese and develop diabetes? In: Bishop MR, editor. Chocolate, Fast Foods and Sweeteners: Consumption \& Health. Commack, New York: Nova Science Publishers, Inc., 2009. Chapter 17, pp. 293-299.

113. Caraher M, Cowburn G. Taxing food: implications for public health nutrition. Public Health Nutr. 2005;8(8):1242-1249.

114. Wang Y, Beydoun MA. The obesity epidemic in the United States gender, age, socioeconomic, racial/ethnic, and geographic characteristics: a systematic review and meta-regression analysis. Epidemiol Rev. 2007;29:6-28.

\section{Publish your work in this journal}

Risk Management and Healthcare Policy is an international, peerreviewed, open access journal focusing on all aspects of public health, policy, and preventative measures to promote good health and improve morbidity and mortality in the population. The journal welcomes submitted papers covering original research, basic science, clinical \& epidemio- logical studies, reviews and evaluations, guidelines, expert opinion and commentary, case reports and extended reports. The manuscript management system is completely online and includes a very quick and fair peerreview system, which is all easy to use. Visit http://www.dovepress.com/ testimonials.php to read real quotes from published authors. 